\title{
Autogestión y participación local en el centro ecoturístico "Cascadas El Corralito", 0xchuc, Chiapas
}

\author{
Julio César Sánchez Morales* \\ Facultad de Ciencias Sociales (Unach) \\ Guillermo Montoya Gómez \\ Eduardo Bello Baltasar \\ El Colegio de la Frontera Sur (Ecosur)
}

\section{Resumen}

El artículo versa sobre las estrategias de gestión, autogestión y participación local de los tseltales de Oxchuc, Chiapas, durante la puesta en marcha del proyecto de turismo alternativo Cascadas El Corralito, que se perfila clave para el desarrollo de capacidades en la gestión y autogestión económica, ambiental y social con respecto a la reapropiación de los recursos naturales. Los tseltales han logrado que el ecoturismo sea reconocido por los gobiernos en turno, han fortalecido sus redes de apoyo y los mecanismos para el cuidado en la conservación de sus recursos naturales, pero aún no logran que la renta de sus servicios ecoturísticos rompa con la dependencia de las transferencias gubernamentales. Sin embargo, han creado mecanismos de mediación y consenso que han posibilitado regular las decisiones claves colectivas y hacer notoria la autogestión, gestión, el control que se hace de la base de recursos naturales y los beneficios en el proyecto ecoturístico. Para el análisis se utilizaron instrumentos metodológicos de corte cualitativo. Entre las técnicas empleadas para la recolección de información se usaron entrevistas a profundidad, etnografías, observación participante y encuestas, de éstas se obtuvieron datos cuantitativos.

\section{Palabras clave}

Consensos, ecoturismo, gestión, participación local, recursos naturales.

Recibido: 31/08/2012 · Aceptado: 17/09/12 


\title{
Self-management and Local Participation in the Ecotourism Center of Waterfalls El Corralito, Oxchuc, Chiapas
}

\author{
Julio César Sánchez Morales \\ Facultad de Ciencias Sociales (Unach) \\ Guillermo Montoya Gómez \\ Eduardo Bello Baltasar \\ El Colegio de la Frontera Sur (Ecosur)
}

\section{Resumen}

This article is based on the management, self-management and local participation strategies of the tzeltal community in Oxchuc, Chiapas, during the launch of the alternative tourist project of Waterfalls El Corralito. It stands as a key for the growth of their financial capacity of management and self-management, as well as social and environmental, with regard to the re-appropriation of natural resources. The tzeltal community has succeeded in the recognition of their ecotourism projects by the local governments and has strengthen its networks of mutual support and their mechanisms of conservation of natural resources. Nevertheless, they have not yet succeeded in achieving their financial independence from government grants through their ecotourism services. However, they have created mechanisms of mediation and consensus, which have enabled them to make key collective decisions and to make known the management, self-management and regulation of natural resources and the benefits of the ecotourism project. A qualitative method is used for the analysis. Among the various techniques used to obtain quantitative data, in-depth interviews, ethnographies, participative observation and surveys were carried out.

\section{Palabras clave}

Consensus, ecotourism, management, local involvement, natural resources. 


\section{Introducción}

\section{Turismo y espacio rural}

Los espacios rurales han sido percibidos históricamente como espacios productivos vinculados a actividades primarias, cuya acusada impresión espacial ha favorecido la identificación del espacio rural como una de sus partes: el espacio agrario (Ivars, 2002; Baidal, 2002; Dachary, 2000; Sevilla, 2006). Sin embargo, los cambios en las actividades productivas han modificado la función económica de tales espacios (Ivar, 2002, Toledo, 2003). Esto produce una transformación sustancial operada en función de una mayor diversificación económica, que implica entre los pobladores una heterogeneidad social y cultural en el acceso, los usos y el control de los recursos naturales. Además, el rezago y la marginación que padecen los pueblos - de los que emana gran parte de la riqueza cultural, social y económica- han hecho que los microproyectos de ecoturismo en zonas rurales coadyuven en parte al desarrollo de capacidades económicas individuales o colectivas, y sean estos un gran reto en la conservación del patrimonio natural y cultural.

Aunque las opiniones están divididas, los posibles beneficios del ecoturismo pueden contribuir al análisis de la necesidad de salvaguardar la biodiversidad y las funciones de los ecosistemas entre las poblaciones que lo impulsan (Gossling, 1999: 303; Boo, 1991; Bringas y Ojeda, 2000; March, 1996, Farell y Runyan, 1991). Esto último se ha observado en estudios de caso en Chiapas, donde se ha discutido la viabilidad de las actividades económicas y su apertura entre las sociedades rurales, particularmente en microproyectos como los centros ecoturísticos. ${ }^{1}$ Desde luego, los análisis pueden ilustrar una diversidad de opiniones, pero dejan en claro el dinamismo interno de los grupos que impulsan la actividad, los reajustes sociales y las estrategias de empoderamiento económico, social y ambiental (Maldonado; 2008; Hernández, 2002; Kutay, 1992; Reygadas et al., 2006; Toledo, Alarcón y Barón, 2002).

A pesar de que los centros ecoturísticos son en su mayoría microempresas familiares, ejidales y comunitarias surgidas de la organización de los propios

${ }^{1}$ Tales casos de estudio son La Sima de las Cotorras, Las Guacamayas, Río Lacanjá, Causas Verdes, Lacanjá Chansayab, Estación Chajul, Escudo Jaguar y Nueva Alianza. 
habitantes, a veces con el apoyo de instituciones estatales y organizaciones académicas y no gubernamentales, estas promueven ahora el respeto a los recursos naturales, la cultura y las actividades tradicionales de sus pueblos, como parte de la oferta al turista (Reygadas et al., 2006: 73). En los procesos donde se incrustan, los sujetos van dando forma a la sustentabilidad social y a un lenguaje común que raya en un mimetismo discursivo sobre la reapropiación de los recursos naturales. Por ello, la situación de los tseltales de la comunidad El Corralito, Oxchuc, Chiapas, no se aleja de esta perspectiva ya suscitada en otros contextos.

Las experiencias en el ecoturismo, de un grupo de 42 miembros de una sociedad cooperativa de productores rurales, muestran rasgos de los cambios a nivel social, cultural y de reapropiación de sus recursos naturales. Lo vivido por los sujetos locales para elevar el bienestar de sus familias son resultado de largas discusiones, consensos, disensos y controversias sobre el fortalecimiento de las capacidades de gestión de conocimiento, autogestión económica y mecanismos de participación colectiva. No obstante, con ello se observan encrucijadas de actividades económicas de diversos tipos (primarias, terciarias) y nuevas dinámicas que involucran factores sociales (participación para lograr consensos o expresar disensos), económicos (exigencias de capital para crecer, orientación y accesibilidad a diferentes mercados), laborales (mano de obra para el mantenimiento, reorganización de recursos humanos bajo la figura empresarial) y culturales.

Pese a las dificultades de toda índole, los indígenas tseltales han recurrido a estrategias adaptativas, resultado del agotamiento de un modelo económico basado en actividades primarias (Fernández, 2000: 3). Con todo, no se alejan de la situación particular de otros espacios rurales, donde las actividades gestadas por sujetos se convierten en estrategias de largo plazo para la diversificación de ingresos, sin que esto excluya las actividades primarias o de transformación (Reygadas et al., 2006: 37).

\section{La comunidad tseltal El Corralito}

La comunidad El Corralito está situada en el municipio de Oxchuc, Chiapas. Tiene alrededor de 1833 habitantes (figura 1). En cuanto a la vegetación, predominan los bosques de pino, encino y liquidámbar; además de una variedad 
de hierbas silvestres que se producen de manera natural, así como frutales: plátano, aguacate, limón, café. Dentro de las especies de flora más características se encuentran el roble de corazón, roble blanco, ocote, caspirol, zapotillo, limoncillo, mutut, epífitas y helechos (Ramos, 2009: 45).

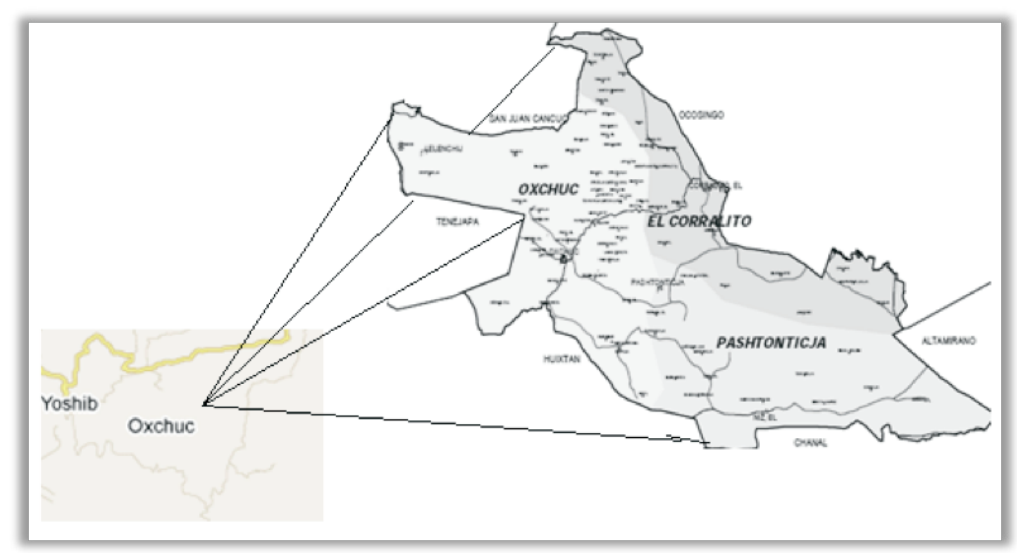

Fuente: Elaboración propia con base en Sedesol (2001) e INEGI (2011)

Figura 1. Microrregiones del municipio de 0xchuc

La comunidad El Corralito tiene una topografía accidentada con variaciones en sus pendientes que van de los 2000 a los $1400 \mathrm{msnm}$. Su clima es templado húmedo con abundantes lluvias en verano, con una temperatura promedio de $16^{\circ} \mathrm{C}$ mínima y $28^{\circ} \mathrm{C}$ máxima. Entre las labores que realiza la población indígena tseltal se encuentran las agrícolas, como la siembra de café y el cultivo de la milpa (maíz y frijol, especialmente para autoconsumo, pero en algunos casos se logran obtener excedentes para la venta); asimismo, se desarrollan actividades relacionadas con el comercio o servicios a la comunidad, como albañilería, artesanal u otras. El Corralito cuenta con un sitio definido para el ecoturismo, llamado "Cascadas El Corralito", con una superficie de $115000 \mathrm{~m}^{2}$.

La principal religión que se practica en esta comunidad es la cristiana evangélica, de denominación presbiteriana. Esta religión llegó entre 1944 y 1947 con la enfermera Florence Gerdel para apoyar el trabajo de Marianna Slocum. Para 1950, aproximadamente la mitad de la población tseltal de Oxchuc se había convertido al presbiterianismo, cosa que no se había logrado en ningún otro municipio (Harman, 1990). 


\section{Metodología}

El estudio fue focalizado y se realizó con 42 tseltales, socios del centro ecoturístico “Cascadas El Corralito”. Entre ellos están aquellas personas que prestan algún servicio turístico, representantes de comités de turismo, pasados y actuales, así como personas ajenas al centro ecoturístico, vecinos de los tseltales. Se utilizaron procedimientos y técnicas cualitativas y cuantitativas, adecuadas a los propósitos específicos del estudio, entre ellos, la entrevista semiestructurada y las encuestas (Ortiz, 1998). El diseño de las guías de entrevistas se probó mediante pruebas piloto, con la finalidad de verificar que durante el trabajo de campo las preguntas estuvieran bien planteadas.

Desde un posicionamiento teórico, tomamos como punto de partida algunas reflexiones de Enrique Leff $(2002,59)$, quien menciona que la reapropiación de los recursos naturales conviene en la aplicación de estrategias dirigidas de actores locales. Esto abre un proceso orientado a la acción de los sujetos involucrados en la construcción de una sustentabilidad basada en los derechos de propiedad y de acceso a los recursos potenciales locales (económicos, ambientales o sociales).

Enrique Leff plantea que la autogestión, la gestión para un desarrollo endógeno local y la gestión participativa de los recursos naturales son vitales. Con estos elementos, la reapropiación social de los recursos naturales se hace operativa, pues se observan estrategias de usos múltiples de la naturaleza y la variedad de sus microambientes, donde se llevan a cabo prácticas productivas que no solo preservan la biodiversidad, sino que elevan el nivel de autosatisfacción de las necesidades materiales de las comunidades.

En los procesos de autogestión participativa, los valores culturales y humanos definen el potencial productivo de proyectos locales. Este tópico parte de la consideración de que la autogestión y la gestión de las comunidades, mediante su participación en estrategias y acciones de los sujetos -como el ecoturismo-, ${ }^{2}$ refuerzan las identidades locales y colectivas, así como el acceso, uso y disfrute de los recursos naturales, económicos o sociales (Leff, 2007). Por ello, los procesos de gestión participativa se han convertido en procesos de aprendizaje que generan beneficios sociales, como el fortalecimiento de los actores y la

2 Para ampliar la discusión sobre este punto, véase Boo, 1991; Bringas y Ojeda, 2000; March, 1997. 
promoción de liderazgos en el seno de la comunidad, la mejora de la gobernabilidad (porque se robustecen los acuerdos entre los diferentes actores sociales, públicos y privados) y la acción concertada que multiplica -y no solo suma- los recursos existentes y aumenta la eficiencia y legitimidad de la gobernanza local. Desde este posicionamiento tratamos de dilucidar la dinámica interna de esta organización de tseltales.

\section{El ecoturismo entre los tseltales}

En el año 2001, un grupo de indígenas tseltales de la comunidad El Corralito, experimentaron una situación inesperada; se enfrentaron al dilema de tomar decisiones respecto a impulsar o no un proyecto ecoturístico en sus tierras, donde la actividad primaria era fundamental. Esta propuesta fue promovida por un personaje a quien ellos llamaban El Marso. ${ }^{3}$ Este agente externo a la comunidad tseltal les propuso crear un centro ecoturístico, dadas las bellezas naturales del lugar: caída de agua, ocho pozas y un área de bosque.

Junto con la propuesta, el agente externo propició una discusión sobre el uso y destino de los recursos naturales en las tierras de los tseltales. Pretendió incentivar a los indígenas con un ingreso económico adicional y formas diferentes de valorar sus recursos naturales (entrevista a Miguel López Mucha, noviembre de 2009). Lo único que solicitaba El Marso era ser integrante del proyecto, para, después, si los tseltales accedían, comprarles las tierras de la zona y ser él quien impulsara el centro ecoturístico con una visión empresarial.

Tras la propuesta, las 87 familias de tseltales -habitantes del territorio, unidos por el parentesco- discutieron y se pusieron de acuerdo. Entre los argumentos se aceptó impulsar el proyecto ecoturístico, no obstante, serían ellos quienes intervendrían en la gestión de sus recursos naturales sin la participación de personas ajenas a sus tierras. En total, solo 42 tseltales aceptaron colaborar, con lo que se formó la Sociedad Cooperativa de Responsabilidad Limitada llamada Xchay'ja' (caída de agua) para impulsar lo que ahora es el centro ecoturístico "Cascadas El Corralito".

\footnotetext{
${ }^{3}$ Su nombre es Hugo Pérez Marzo, mestizo proveniente del Estado de México que reside desde hace 20 años en la zona de Oxchuc, en la comunidad Mesbilja. Actualmente impulsa talleres entre indígenas que quieran trabajar el ámbar, la plata u otros productos, con la finalidad de generar autoempleo.
} 
Hasta antes de 2002, los tseltales se relacionaban con sus recursos naturales desarrollando algunas actividades de agricultura o cría de animales domésticos. Hasta entonces no veían la posibilidad de aprovechar sus bellezas naturales, muy propicias para la actividad turística, mucho menos consideraban que la caída de agua que forma una cascada condensara en sí misma su belleza escénica y un valor de uso con potenciales costos de oportunidad. El cuerpo de agua que atraviesa parte de su territorio había sido percibido solo como un servicio más que la naturaleza les prodigaba y que, en su reproducción biológica, les ayudaba a cubrir sus necesidades. Sin embargo, pronto cobraría presencia e importancia no solo en sus esquemas de pensamiento, sino en el resto del cuerpo social. Se descubre, así, en el recurso agua, una función socioeconómica que más adelante incluirá la dimensión ambiental. Además, como se dijo, el río forma a su paso una cascada y ocho pozas con características muy peculiares, además de un área boscosa singular por ubicarse en una zona de transición, es decir, una zona de bosque de niebla.

Entre las experiencias del ecoturismo de los tseltales está la nueva forma de ver la cascada, ya que implica otras posibilidades para la dinámica comunal, constituyéndose en un nuevo proyecto de vida colectivo, cada vez más objetivo. Esto ha ocasionado que se desplieguen estrategias de trabajo conjunto, mecanismos de recohesión social, capacidad de agencia y gestión para impulsar esta actividad y promover el proyecto ante instancias de gobierno (local y estatal), sin dejar de lado sus actividades habituales de agricultores, jornaleros, maestros o comerciantes. La evidencia empírica demuestra que los tseltales de El Corralito lograron reapropiarse del recurso agua. Esta y otras experiencias del grupo hacen revisualizar los contextos rurales (Toledo, 2000) frente a otro escenario global, social y ambiental, donde los recursos naturales se han vuelto más escasos por su uso irracional o por la contaminación que han padecido.

En 2002 los tseltales deciden aventurarse a impulsar el ecoturismo en sus tierras. Desde entonces han pasado por etapas de desarrollo y se han dado saltos cualitativos hacia un proceso incipiente de gestión ambiental y modos de apropiación de un proyecto económico endógeno, porque sus ingresos ya no solo dependen de sus actividades primarias, comerciales o de venta de fuerza de trabajo en las áreas urbanas, sino que la actividad ecoturística se erige como una fuente más. Aunque este grupo indígena comienza con una nula 
experiencia en el ramo turístico y pese a que se equipara con las vivencias de otros grupos en el estado de Chiapas, que han impulsado el ecoturismo y desarrollado procesos de revalorización de los territorios (López y Palomino, 2000; Maldonado, 2008), reapropiación y reúso de los recursos naturales básicos para la existencia (Toledo et al., 2000), no están ajenos a las readecuaciones estructurales de los colectivos, en el sentido de que requieren construir instituciones internas para la toma de decisiones -asamblea-, la estructuración de comisiones, la apropiación de nuevos discursos y lenguajes de valoración en torno a los recursos naturales disponibles (Maldonado, 2008; Hernández, 2002; Kutay, 1992; Reygadas et al., 2006; Toledo, Alarcón y Barón, 2002).

La promoción del ecoturismo ha traído aparejada mecanismos de cohesión social, equiparables con aquellos centros ecoturísticos que han tenido en los últimos años un repunte en las preferencias de los turistas, principalmente porque el centro está ubicado rumbo a Palenque a la orilla de la carretera San Cristóbal-Ocosingo, una ruta muy transitada.

En general, los esfuerzos en infraestructura y procesos de gestión y autogestión del proyecto en cuestión significan un proceso de experimentación y una reestructuración social consensuada, en la medida en que no se trastoca la convivencia interna ni el tejido social sobre el que se reproduce el colectivo comunitario ligado a las actividades de ecoturismo. Hacer esto conlleva, a la postre, obtener resultados de índole social, económica o turística que reflejen la gestión de recursos naturales y una fuerte participación en la conservación del proyecto ecoturístico y de los recursos naturales, como a continuación explicaremos.

\section{Fase primera: reapropiación y mecanismos de mediación y autogestión de recursos naturales}

El proyecto en el mediano plazo revela varias fases recorridas y otras por transitar. La fase inicial o de reapropiación y de experiencias, la fase de construcción de consensos y mecanismos de mediación y, por último, la fase de la consolidación. Las evidencias empíricas señalan que el proceso de reapropiación es aun endeble en términos económicos; en cuanto a lo social, se dio sin mayor dificultad una especie de absorción y reacomodo a las exigencias estructurales y funcionales en la vida colectiva, familiar e individual; en el aspecto ambiental, 
hasta ahora hay un mimetismo discursivo que raya en la conservación y preservación de los recursos naturales.

Entre los tseltales la autogestión, desde 2002, constituye un proceso participativo relacionado con el ejercicio del consenso y la toma de decisiones de sus más variados componentes sociales e individuales. El proceso de organización cristalizado en el impulso del proyecto ecoturístico ha fructificado en avances internos -diversificación en la estructura de ingresos, ampliación del capital físico, social y humano- y externos, tanto de la participación de las mujeres, como de jóvenes y ancianos.

La mera participación del grupo en el proceso decisorio de gestión de sus recursos naturales no determina que estos cristalicen en etapas de autogestión sólidas. Solo la estructuración de las características y condiciones en la práctica social concreta de la participación puede definir su carácter y sus tendencias. Sin embargo, durante el proceso autogestivo, se puede observar que la regencia de su destino como grupo (re)organizado, a partir de la inclusión de todos los agentes (hombres y mujeres), incidió en la satisfacción de sus necesidades e intereses colectivos. Por ejemplo, desde 2001 se aprecian los síntomas de una cohesión social que incide en una reestructuración consensuada de la vida organizativa entre los tseltales, lo que da paso a prácticas de cooperación en el resguardo de las tierras, aguas y bosques. Don Miguel relata así su experiencia:

Fueron pocos los que no queríamos, no lo creíamos pues que hubiera beneficio, ya el Marso nos invitaba a asociarnos y crear lo que tú ves, pero los más hermanos no querían, teníamos temor que nos quitaran nuestra tierra; pero no fue así, mi hermano Nicolás decía que no se podía quitar, que el ley no permitía eso, tenemos el papeles que dicen que es de nosotros [...] pasó uuuy, mucho después, había mucha necesidad, entonces lo que sucedió fue que nos echaron un grito que iba a haber asamblea para discutir, fue mi hermano Nicolás que nos invitó, que dijo: "ya es hora de hablar sobre lo que nos conviene”, así pues durante la reunión llegaron todos los Mucha... uy más de 80, aparte mujeres, muchos hablaron para contar cómo hacerle, muchos se enojaron, otros preguntaban, útale, era un discusión entre todos: y así empezó todo, fue difícil acordar algo, pues muchos no quisieron cooperar para el gestoría y comenzar, pero se logró y el mayoría le entró, solo el otro uno el Marso ya no se le aceptó, pues no es del linaje Mucha, y se fue; y algunos de mis 
primos y hermanos no quisieron, ya después quisieron pero ya habíamos cooperado mucho, no quisieron ponerse al tanto [...] El Marso seguía después insistiendo que traería técnicos, maestros, mucho grinko, pero ya estaba que no queríamos no al Marso y solos caminaremos, así es el tradición acá, y así fue que los Muchas nos aventamos al gestoría y platicar siempre de los problemas de cómo hacerle [entrevista, junio de 2009].

\section{Asamblea local y participación}

Entre los años 2001 y 2002 se observaron cambios en el grupo y en la reapropiación de los recursos naturales en el centro ecoturístico. Factores como la nula experiencia de los tseltales en el campo del ecoturismo y la falta de interiorización de sus bellezas naturales obligaron a crear la asamblea y las reglas de participación en cargos de la mesa directiva, con la finalidad de tomar decisiones respecto del uso colectivo y los recursos naturales.

La participación de los miembros de la comunidad en la discusión de sus derechos, aspiraciones y sueños, reconociendo sus debilidades, particularidades y fortalezas como grupo, registró diversas expresiones organizativas (desde la familia, la sociedad cooperativa y la asamblea general) y visiones centradas en un trabajo colectivo e individual. Esto destacó la importancia de la concientización del trabajo en conjunto y de los niveles de participación incluyentes para hombres, mujeres, jóvenes y ancianos.

Aunque durante el proceso siempre se mantuvieron los consensos, disensos o controversias, las discusiones han sido un esfuerzo colectivo que ha provocado un arraigo de protección e iniciativas ligadas a estrategias defensivas de su propiedad (tierras) y las fronteras de los recursos naturales (límites entre indígenas tseltales de otras comunidades de Oxchuc), por ejemplo, no permitir la entrada al trabajo colectivo de gente no pariente o socia; de territorialidad y propiedad comunal de tierras, agua y bosques (a pesar de tener límites de tierras, ahora como centro ecoturístico estos se borran y hay libre tránsito de los turistas), así como la discusión acerca de cómo delimitar las fronteras naturales entre los tseltales, pues con la venta de servicios turísticos los recursos naturales tendrían una función estética y no productora de bienes de autoconsumo, al menos no como antes. 
Hasta antes del 2001, los recursos naturales (las tierras, el agua, los bosques) fueron para los tseltales bienes de uso colectivo y para autoconsumo de las familias. La milpa, el cultivo del café, la leña, el agua del río para lavar ropa no se consideraban dentro de las estrategias y condiciones de preservación que impone la actividad turística. Los derechos legales de propiedad y las formas concretas de acceso, posesión, apropiación y aprovechamiento de los recursos naturales se basaban en reglas consuetudinarias. Hasta ese momento no se consideraba la existencia de un escenario social sobre la apropiación de los recursos bajo un nuevo concepto de producción fundado en la valoración de los potenciales ecológicos y culturales para la venta de servicios turísticos. Para ejemplificar esto, es útil ver lo que ocurría con el uso de la leña y del agua: antes de la creación del centro ecoturístico se empleaba leña solo para el autoconsumo. En una muestra aleatoria, al preguntar si extraían leña o madera, $75 \%$ de los entrevistados no dudó en responder afirmativamente, señalando que la extraía del bosque, mientras que 25 \% respondió negativamente. Estos últimos mencionaron que la compraban.

Del 75 \% de los que afirmaron un uso del bosque, $13 \%$ empleaba la madera para construir cercas, mojones y postes para delimitar sus parcelas. El resto, para consumo doméstico. Respecto al uso del río, principal atractivo turístico, antes de la creación del centro ecoturístico su uso también era para autoconsumo. Este se complementaba con los "ojos de agua" que igualmente utilizaban para beber. La justificación del uso del río fue que pasaba por sus tierras, por lo que se le aprovechaba para el consumo familiar. De los entrevistados, 60 \% menciona que las mujeres utilizaban el río para lavar la ropa y para otras necesidades domésticas, $20 \%$ lo utilizaba para bañarse. Aunque las tierras estaban parceladas y con límites naturales, los ahora socios del centro, al ser parientes, no se oponían a que entraran a bañarse si las zonas para tal uso se encontraban en sus tierras. Finalmente, $15 \%$ mencionó que eran usadas para irrigar la milpa u otro cultivo, aunque esto fue en muy pocas ocasiones, pues el tipo de agricultura desarrollada por los tseltales es extensiva.

Antes de la creación del centro ecoturístico, los recursos naturales en tierras de los tseltales solo tenían un valor de uso, intangible y hereditario. Entre 60 y $75 \%$ usaba los recursos tierra, agua y bosque para la producción de bienes de

${ }^{4}$ Comúnmente se les llama así a los lugares donde brota el agua. 
autoconsumo: maíz, frijol, café, leña y agua para beber. Los recursos naturales eran independientes de cualquier proyecto de desarrollo económico endógeno, y no tenían proyección hacia la obtención de ingresos monetarios. La naturaleza desempeñaba una función: brindar servicios para el consumo humano.

\section{Resguardo de los recursos naturales en el centro ecoturístico}

Como grupo (re)organizado bajo una figura jurídica se enfrentaron a cómo lograr la autonomía en el reúso de sus recursos naturales. Aquí se mezcla lo privado con lo público. Por ejemplo, si antes las mujeres lavaban ropa en el río en cualquier horario y lugar, ahora se hace de madrugada y en lugares donde no se den cuenta los turistas, o bien se debe acarrear agua y lavar en sus casas. Asimismo, la extracción de madera, leña u otros productos no se hará sin previa consulta de la asamblea. En sus inicios, esto provocó desacuerdos, disgustos y rupturas, no profundas, entre los socios. No obstante, a la larga se asumió que tales reglas no escritas serían en beneficio colectivo, pues al conservar tales recursos el dinero sobrevendría de la venta de servicios turísticos. Aunque las tierras de los socios fueran "propiedad privada", y en ellas hubiera fragmentos de bosque, se tenía que consultar sobre el uso, particularmente en los aspectos mencionados. En estricto sentido, tales reglas no se realizaban en su totalidad, pero con el paso del tiempo y la visible llegada de turistas para contemplar las bellezas naturales se obligaron a concretarlas, sustituyendo el uso por la compra de tales bienes de consumo.

En esta primera fase, los tres o cuatro años iniciales, hubo factores positivos de sustentabilidad y reapropiación social de los recursos naturales: la consolidación de acuerdos y el consenso entre jóvenes, mujeres, adultos y ancianos. Con esto se dio paso hacia un capital social (traducido en confianza, asociatividad y conciencia), que fortalece la idea de un proyecto ecoturístico local de estilo familiar (Reygadas et al., 2006), pensado para no "perder derechos" de sus tierras, aguas y bosques, y que a futuro sea un incentivo económico para los hijos.

Se atestiguó también el surgimiento de un espacio para, desde su cotidianidad y prácticas de vida como grupo étnico tseltal, reafirmar el proceso de reelaboración colectiva de propuestas encaminadas a la reivindicación, de consensos y discusiones, al fortalecimiento de un proyecto que ahora quieren heredar a sus hijos y que ven viable: el centro ecoturístico "Cascadas El Corralito”. 
Desde luego, este grupo tseltal se apodera de un cuerpo de prácticas (limpia de los márgenes del río, plantación de frutales diferentes de la zona, cuidado de los árboles y el río) y conocimientos orientados a posiciones acerca del control social del territorio y de los recursos naturales.

Esto fue necesario al inicio para el fortalecimiento endógeno de capacidades, de autonomía, autodeterminación de sus necesidades y autogestión del potencial ecológico (Leff, 2007), aun con sus debilidades, como fueron la ya mencionada nula experiencia, los intereses personales, las envidias, los chismes, la falta de publicidad, de capital y de un convencimiento total de la colectividad acerca de lo que se estaba haciendo. No obstante, se observa que estos factores, en los primeros años de vida del proyecto, ya son avances significativos hacia una reapropiación social de recursos naturales y de una sustentabilidad social, aunque marcados por incipientes reglas de uso y conservación; asimismo, sellados por un interés legítimo y genuino de reapropiarse de lo suyo, que es la herencia de los padres y el futuro de los hijos: tierras, aguas y bosques.

\section{Fase segunda: construcción de consensos y mecanismos de mediación}

Entre 2003 y 2006 se observa la solidez de las redes de apoyo mutuo, confianza, autoinclusión de jóvenes, adultos, mujeres, ancianos y una estructura de derechos y obligaciones de todos los socios para el proyecto. Surgen nuevas reglas y normas de dirección respecto al trabajo colectivo, el resguardo de los recursos que dan vida al centro turístico y la búsqueda de capital de inversión en instituciones de gobierno, para ampliar la infraestructura de base. En esta etapa se consolidan las capacitaciones para el resguardo de los recursos naturales y la siembra de especies de frutas y árboles desconocidos en la zona. Los recursos naturales quedan encerrados dentro del proyecto turístico y ahora tienen doble función: seguir dando sus frutos en menor medida (valor de uso) y la venta de su belleza (valor de cambio/venta de servicios turísticos). Según Álvaro López, socio del centro ecoturístico, después de varios años se dio prioridad al centro ecoturístico, "los recursos naturales ya existen, solo hay que mantenerlos en buen estado, limpios, pues” (entrevista, junio de 2010). Paradójicamente se observa desánimo para la consecución del proyecto en su largo alcance. Hay una expectativa de la prosperidad en el aspecto económico que se sostiene por la

$$
\text { expectativa de la prosperidad en el aspecto económico que se sostiene por la }
$$


voluntad pasiva y colectiva de los ancianos y las mujeres tseltales. Si bien hay desesperanza, también se ha fortalecido la colaboración a través de las redes de apoyo mutuo y, por ende, la consecución y la perseverancia.

Los factores que contribuyeron al desaliento entre algunos socios fueron el intervencionismo y la no comprensión del idioma español. Las constantes intervenciones por parte de las instituciones de gobierno para regular sus actividades crearon una red de nociones que ellos jamás habían escuchado. Se habló de modelos (ecosistemas y estrategias de conservación), actores (prospectores, taxonomistas, planificadores y expertos) y estrategias (manejo de recursos, derechos de propiedad) (entrevista a Álvaro López, julio de 2010). Estas intervenciones motivaron traducciones acerca de cómo trabajar y entender el ecoturismo. Algunos socios se desilusionaron, pues su condición de agricultores y la falta de instrucción académica los imposibilitó para comprender de qué trataban las capacitaciones o los mensajes. Luego, la presión de diferentes actores externos, como universidades, centros de investigación, organismos no gubernamentales, que observaron en este nuevo centro ecoturístico un modelo para estudios sociales, culturales o económicos, fue acorralando a los tseltales. Esto comenta Juan López, joven socio de la sociedad cooperativa:

Casi siempre vienen estudiantes, investigadores, o maestros y siempre nos preguntan asombrados cómo le hicimos; que está muy grande, que cómo conservamos, para qué, cuándo, que qué es el turismo, cultura, y así, a veces nos reímos porque siempre son lo mismo [...] y lo mismo les decimos [...] a veces ya ni sabemos qué decir, a veces nos toman como ejemplo, quieren saber por qué somos tseltales 0 organizados, pero ya aburre siempre lo mismo, si no es el gobierno, son los profesores, si no, los estudiantes, así que nunca falta alguien que venga. Ya sabemos cómo son: pantalón de mezclilla, muy amables, con cámaras, cuadernos o grabadoras. Pero no sabemos qué decir solo que cuidamos lo que Dios nos dio [...] así pues muchos tíos por eso ya no quieren, les da pena y se desaniman.

Por lo anterior, los tseltales optaron por adaptarse y crear estrategias que dan por resultado el surgimiento de capacidades y habilidades discursivas, aunque adaptadas a sus necesidades. En la práctica, en esta etapa hubo experiencias que representaron nuevamente consensos, disensos, fracasos, pero también éxitos en la capacidad de agencia (creación de cuatro nuevas palapas y recursos económicos para infraestructura dañada) y procesos de interiorización y revaloración de 
sus bellezas naturales (aunque a nivel discursivo y en algunas prácticas incipientes de conservación). Se observan procesos nacientes de gobernanza ambiental mediados por la endogenización del proyecto de turismo, y la necesidad colectiva de reapropiarse de sus tierras, aguas y bosques, constituidos en patrimonio natural y cultural.

Por otra parte, las prácticas de trabajo colectivo, uso de los recursos naturales y transparencia financiera ahora son más eficientes. Estos hallazgos refuerzan la propuesta de Enrique Leff (2002) acerca de los derechos de propiedad, que se definen como resultado de las estrategias de capital social y poder local, pues se encaminan a prácticas alternativas de uso de los recursos naturales y dependen de condiciones culturales y sociales diferenciadas. En este sentido, ya aterrizadas por los tzeltales, estas ideas hacia una gestión de recursos naturales se reflejan en el principio de equidad como articulación de la diversidad (Leff, 2009: 69) y los derechos de propiedad del grupo étnico, transfigurados en estrategias de poder frente a otros grupos tseltales aledaños, además de las estrategias discursivas creadas para la consolidación de un proyecto económico. Esto no quiere decir que no hayan existido problemas, desánimo, deserciones o frustraciones al no obtener el resultado económico deseado, pues los intereses son heterogéneos dentro de este grupo social. Hay necesidades, demandas y derechos particulares. No obstante, a lo largo de los años los tseltales han aprendido que la unidad y la paciencia entre ellos demuestran fortalezas en la autodeterminación de sus territorios y recursos naturales. Por ello, a partir de sus necesidades propiciaron la autogestión del potencial ecológico de su comunidad. A través de la experiencia del ecoturismo han trascendido a un proceso mayor de gestión y participación encaminado a una sustentabilidad ambiental fundada en principios de diversidad ecológica, cultural y social.

Por el momento, tras vencer obstáculos, aprovechar su herencia cultural, fortalecer su "comunidad" y revisualizar su ecosistema, ellos conciben un potencial en la conservación de sus "naturalezas" ligadas al ecoturismo, tal como dice el tseltal Álvaro López. En el plano académico se puede entender que los tseltales, independientemente de su situación en el espacio (formación social) y en el tiempo (momento histórico), se apropiaron, circularon, transformaron y consumieron materiales y/o energías provenientes del mundo natural (Toledo, 2008: 3). Esto muestra un uso colectivo de los recursos naturales dentro de una misma sociedad, donde se comparten el agua, el bosque y la tierra. 


\section{Fase tercera: transferencias económicas, generación de recursos económicos y transparencia en el manejo de recursos económicos}

En los últimos años (hasta 2010) se ha observado una interdependencia sólida entre participación social, proyecto turístico y recursos naturales, pero a la vez se ha experimentado una etapa de estancamiento, pues las circunstancias del mercado, la ley de la oferta y la demanda crea desánimo, desesperanza y migración. Se creyó que los turistas llegarían con la creación del centro, sin embargo no fue así. Se requerían estrategias de mercado: publicidad, convenios con las transportadoras turísticas y que se incluyera el centro ecoturístico dentro de la ruta turística San Cristóbal-Ocosingo-Palenque. Pese a la construcción de carreteras pavimentadas y caminos de terracería, hay muy pocos visitantes, la mayoría de estos llegan a rutas y destinos conocidos y consolidados: Palenque, Montebello, Bonampak y Yaxchilán, por mencionar algunos.

En cuanto a los apoyos gubernamentales, se logró crear las primeras palapas, andadores, restaurante y baños. Empero, los nulos resultados debido a los factores mencionados fueron causas de aislamiento. Por consiguiente, su articulación con programas locales y regionales de desarrollo es todavía una asignatura pendiente, lo que ha limitado el fortalecimiento del capital de inversión y el usufructo de la renta de los recursos naturales a mayor nivel. Si a esto se le agrega la falta de infraestructura de servicios como internet, teléfono, agua potable o tiendas, se evidencia un problema mayúsculo. En ninguno de los casos hubo avances. No se contaba con el capital financiero para poder invertir. A manera de ilustración, en el cuadro 1 se pone de manifiesto que hay un mínimo avance financiero respecto de la captación monetaria del ecoturismo, lo cual imposibilita la reinversión.

La información del cuadro 1 se aplicó a 71 \% de los socios (albañiles, campesinos, choferes, etc.) que se encontraban en la comunidad. Estos resultados dan una visión heterogénea del grupo de trabajo, visión sumamente útil para entender el manejo diversificado de los recursos naturales que llevan a cabo los pobladores del área, pero que muestra las desigualdades en la obtención de recursos económicos. Por ejemplo, un jornalero dedica un total de 628 jornales anuales, ya sea su propia fuerza de trabajo o a través de la contratación de mano de obra, para la implementación de seis actividades productivas, con un 
Cuadro 1. Cálculo del esfuerzo invertido (número de jornales al año) y de los bienes y servicios obtenidos (valor monetario en pesos por año) para las seis actividades realizadas entre los

tseltales de El Corralito

\begin{tabular}{|c|c|c|c|c|c|c|c|c|}
\hline \multicolumn{9}{|c|}{ Valor monetario } \\
\hline & & & Total & & & & Autosub. & Mercado \\
\hline & Jornales & $\%$ & $\$$ & $\%$ & $\$$ & $\%$ & $\$$ & $\%$ \\
\hline Milpa & 130.5 & 20.76 & 7830.00 & 15.72 & 7830.00 & 53.43 & & \\
\hline Café & 27 & 4.30 & 2160.00 & 4.34 & & & 2160.00 & 6.14 \\
\hline $\begin{array}{l}\text { Extracción } \\
\text { de leña }\end{array}$ & 28 & 4.46 & 728.00 & 1.46 & 728.00 & 4.97 & & \\
\hline $\begin{array}{l}\text { Trabajo } \\
\text { asalariado }\end{array}$ & 275 & 43.75 & 33000 & 66.25 & & & 33000.00 & 93.86 \\
\hline Ecoturismo & 72 & 11.46 & 3600.00 & 7.23 & 3600.00 & 24.57 & & \\
\hline Huerto & 96 & 15.27 & 2496.00 & 5.01 & 2496.00 & 17.03 & & \\
\hline Total & 628 & 100.00 & 49814.00 & 100 & 14654.00 & 100.00 & 35160.00 & 100 \\
\hline Porcentaje & & & $100 \%$ & & $29.42 \%$ & & $77.81 \%$ & \\
\hline
\end{tabular}

valor monetario de 49814 pesos anuales. De esos días trabajados, $29.42 \%$ es dedicado a actividades de autoconsumo (milpa, huertos familiares, extracción de leña), mientras que $77.81 \%$ son jornales empleados en actividades orientadas al mercado (bienes, servicios o trabajo temporal fuera de sus comunidades). En el ecoturismo invierte $11.4 \%$ de jornales. Cada jornal invertido en este sector equivale a 50 pesos. Para los tzeltales, el ecoturismo es parte de los ingresos para el autoconsumo (24.5\%). La venta de fuerza de trabajo para el mercado representa $93.86 \%$. Solo $6.1 \%$ es para la venta de café, para quienes tienen cafetales y obtienen algo de producción.

Lo anterior presenta a una sociedad que depende de la venta de fuerza de trabajo para sostenerse. Por lo tanto, no pueden sustituir las transferencias monetarias que pudieran llegar del gobierno. No hay excedentes que vengan del ecoturismo, menos aún para invertir en infraestructura. Si se agrega que 35 160 pesos anuales se utilizan para educación (útiles escolares, imprevistos, luz, etc.), transporte, enfermedades, y que las familias de los socios tienen entre cinco y seis miembros, el panorama no es alentador. Los 3600 pesos anuales que obtienen del ecoturismo les ayudan poco a sus necesidades diarias. Se 
puede pensar que hay un abandono de los tseltales al proyecto, pero no es así. Paradójicamente, las redes de apoyo se encaminan poco a poco y no dejan de funcionar, aunque el entusiasmo disminuye, se sigue participando y aprendiendo del proyecto. Aunque mínima, la inclusión del ecoturismo en la gestión de capital contribuye a la diversificación económica.

Después de diez años, y tras las experiencias de los tseltales de este centro ecoturístico, las instituciones gubernamentales han sido cautelosas en la inversión de capital en este centro. Sin embargo, los tseltales han creado sus propias formas de generar capital, por ejemplo una "caja de ahorro", como ellos dicen, con la cual, aun sin muchas aportaciones, los miembros han conseguido el capital mínimo para restaurar postes, cadenas, sillas o pintura. Asimismo, las peticiones sobre capacitaciones, apoyo logístico en turismo alternativo y administración de recursos financieros son mayores. Resulta paradójico que, frente a un mínimo avance económico en el ecoturismo, hay un proceso con efectos sobre su cultura (mitos, leyendas de las cuevas, agua y bosques), sus recursos naturales y las prácticas de "conservación” (limpia de márgenes del río, no lavar, inserción de árboles frutales y discursos sobre la conservación, no contaminar, no ensuciar el agua, aprovechar lo que la tierra ofrece).

Hay una reapropiación de sus medios culturales (vestimenta, lengua, identidad, cosmovisión, tradición oral, costumbres) y ecológicos de producción (milpa y cacería), mediadas por una autogestión que expresa demandas por la revalorización de sus prácticas tradicionales de uso de los recursos. A pesar de que este proceso no es homogéneo en todos los socios, sí deja un saber necesario en cuanto a la formación de recursos humanos en la dimensión del ecoturismo y la problemática ambiental. La interiorización de los recursos naturales está marcada por un proceso difuso, forzado por actores externos sobre lo que representan los recursos naturales entre los indígenas. Esta interiorización de sus bellezas naturales ha sido al mismo tiempo la debilidad y fortaleza del proyecto de ecoturismo; no obstante, tal como sugiere Leff (2009), se ha impuesto paulatinamente la racionalización social que, frente a las dudas y desconocimientos, se posiciona con la construcción de un saber, ahora resignificado por identidades culturales locales. 


\section{Ecoturismo: opción endógena de revaloración de los recursos naturales}

Se puede considerar, de acuerdo con Reygadas et al. (2006), que el ecoturismo ha sido una de las opciones que las poblaciones locales han elegido como vía para simultáneamente obtener ingresos económicos y cumplir con el cuidado del medio ambiente, en parte por una fuerte demanda del gobierno mexicano y de organismos nacionales e internacionales dedicados a la conservación ambiental. Se trata de una opción endógena que además se basa en la revalorización del espacio desde sus dimensiones culturales y ecológicas. Además, las fortalezas y debilidades se practican mediante un modelo cerrado tipo monopolio familiar, según la clasificación que hicieran Reygadas et al. (2006) para los centros ecoturísticos de la región de la selva de Chiapas. Esto hace que el uso colectivo y la reapropiación social de los recursos naturales sean rentables al nivel del capital social y de la gestión participativa para proyectos endógenos focalizados.

Así, el ecoturismo desarrollado entre los tseltales, si bien es dependiente de recursos financieros, ha fortalecido implícitamente las redes de apoyo mutuo y las aspiraciones de consolidación en la conservación de sus recursos naturales, ahora que son reconocidos como potenciales para la renta de servicios turísticos. Las experiencias en este proyecto ecoturístico indígena muestran la participación de una amplia gama de actores para generar y circular saberes que dan pie a determinadas tomas de decisiones de largo plazo en torno a la gestión ambiental. Por el momento, entre los tseltales involucrados se visualiza que este proyecto, con sus debilidades y fortalezas, es una solución endógena de desarrollo de capacidades locales con carácter estructural, aunque aún limitado, porque no es extensivo ni universal a toda la comunidad tseltal de El Corralito, pero no por ello deja de representar una vía que puede generar un efecto demostración en la microrregión de los Altos de Chiapas, pues en esta región hay zonas indígenas con recursos naturales potenciales para la venta de servicios turísticos, lo que a la postre, sin duda, motivará a otras comunidades a explorar tal potencial e interiorizar la necesidad de reapropiación de los mismos.

Por ahora, las fortalezas y debilidades hacia una reapropiación local de los recursos naturales mediante el ecoturismo ponen énfasis en la organización, liderazgo, financiamiento, permanencia, heterogeneidad, dinamismo interno y control y toma de decisiones. Pese a que hay normas no escritas en la determinación 
colectiva de los recursos naturales, en este grupo tseltal se demuestra que estas permiten mayor movilidad en la gestión de los mismos, no obstante su visibilidad en acciones y mecanismos de resolución de conflictos, de acceso y bajo costo en el uso no parezcan importantes (tal es el caso del uso del agua y la leña y, después, del centro ecoturístico). Otro avance es el reconocimiento mínimo por parte de las autoridades externas -sobre todo del gobierno- de los tseltales en la gestión de recursos económicos y naturales. Esto expone los niveles organizacionales que bajo una estructura de liderazgos está centrada en la participación funcional, sin rupturas en el interior del grupo social.

\section{Reflexiones finales}

Los datos revelan que con la implementación del centro ecoturístico, los tseltales han iniciado la reapropiación social de sus recursos naturales, lo cual significó un proceso de participación y reestructuración social consensuada, porque no ha habido conflictos que trastoquen la convivencia interna ni el tejido social sobre el que se reproduce el colectivo comunitario. No obstante, no los ha eximido de complejos procesos de recomposición de su calendario socioproductivo, comprimiendo o alargando el calendario tradicional-cultural para darle cabida a una actividad otrora ajena a la cotidianeidad en la agricultura. Comprimiendo porque toda diversificación de acciones demanda no solo tiempos, sino espacios para su desenvolvimiento, así como fuerza de trabajo adicional, inversión monetaria efectiva, coordinación, liderazgo y capacidad de gestión. Alargando porque los costos de oportunidad, determinados por el diferencial de ingresos, requieren atender todas las oportunidades de antaño y las nuevas, fincadas estas últimas en labores donde la demanda exige calidad, continuidad y actitud.

Si bien el proyecto aún adolece de debilidades y amenazas, lo realizado ha derivado en ganancia de experiencia y autogestión, ampliación de la infraestructura, visibilidad en el creciente mercado de servicios de ecoturismo que, en esa ruta, es altamente competitivo, no solo por las bellezas escénicas que existen, sino por la entrada de nuevos competidores. Como ocurre con el ciclo del turismo, son tres las temporadas altas y durante el resto del año las visitas son casi de fin de semana. Ello hace un tanto vulnerable la iniciativa. De esta manera, las transferencias de recursos gubernamentales para ampliar el capital 
físico se vuelven apremiantes, lo cual es un problema, pues inhibe la posibilidad de formar un fondo de reserva para reposición y atención de emergencias y contingencias (lluvias, inundaciones o daño de infraestructura de las palapas). Esta dependencia financiera obliga a los socios a buscar y no abandonar las actividades que les procuran ingresos adicionales, en especial la venta de su fuerza de trabajo en las zonas urbanas.

Los avances de los tseltales en estos años son significativos. A lo largo de su trabajo colaborativo han obtenido resultados reflejados en estrategias de usos múltiples de la naturaleza y de la variedad de sus microambientes donde se desarrollan prácticas productivas (Leff, 2002). Algunas pautas de comportamientos ligados a la preservación y valoración de sus recursos naturales indican logros auténticos como grupo reorganizado, vía el ecoturismo. Aquí, en comparación con las experiencias de ecoturismo de grupos organizados en otros sitios, como los de la región selva, no hay una ruptura en el orden social, en parte por pertenecer a una sola unidad familiar (Montoya, Hernández y García, 2010: 25). Esta fortaleza hace frente a la economización de la naturaleza, y ha permitido que, en su contexto local y de acuerdo con sus intereses, redefinan los recursos naturales a ser gerenciados (Escobar, 1999: 81). Sin embargo, no se desestima que haya discusiones, tensiones y molestias, que hasta el momento han sido superadas en el camino hacia una sustentabilidad fuerte (Allier y Roca, 2009: 45).

La participación local y los procesos de autogestión de los recursos naturales no han sido fáciles. Lo interesante es que los tseltales han construido una estrategia alternativa con su capital natural. Esta fortaleza es en sí misma parte de un proceso inicialmente muy ajeno a sus vidas, que tuvo que reordenar su trabajo en jornales, en el comercio, en el magisterio y en la agricultura. No obstante, la tierra, el agua y los recursos forestales que rodean el río, de estar en reposo o en una fase de letargo que no objetivaba su valor de uso y, luego, su valor de cambio, ocuparon un lugar prominente no solo en el discurso sino en la acción y reorganización de los 42 socios.

En algunos de los casos, el centro ecoturístico ha adquirido significado que evoca, tal como ellos dicen, una bendición, una opción de vida, una utopía, que vendrá en el futuro a jugar una función en la reproducción colectiva e individual del grupo social, pues será "herencia para mis hijos" (entrevista a Juan López Mucha, junio de 2010). Así, en la simbiosis participación social- 
ecoturismo-ecursos naturales hay lo que Rosa Hernández (2002) apunta: un proceso autogestivo y de adaptación social y nuevos lenguajes de valoración, propios de una reapropiación social de los recursos naturales. Esto último se ha perfilado a lo largo de diez años mediante estrategias de gestión participativa sobre sus recursos naturales, dirigidas por actores locales.

Cabe insistir en que, si bien los recursos monetarios son insuficientes, el esfuerzo de los tseltales ha logrado ampliar su cobertura y la demanda de servicios en el mediano plazo para pensarse como un proyecto alternativo de vida.

Los tseltales le apostaron a lo no inmediato, y en ello se puede destacar una visión de futuro, distinta por mucho de la que les heredaron sus padres y abuelos, plenamente aferrada al control de esa belleza escénica que identificaron como algo dado. En el fondo se trataba de intentos de dejar lo que eran (si es que eran algo, a los ojos de sus vecinos y ladinos): campesinos pobres con escasa tierra, cuya única esperanza era ir a buscar trabajo fuera de la comunidad. Por lo mismo, el proyecto en el mediano plazo revela varias fases recorridas y aún por transitar: la fase inicial o de reapropiación, la de la ampliación y adquisición de experiencia y la de mayor envergadura: la de la consolidación. Las evidencias empíricas señalan que el proceso de reapropiación todavía es endeble en términos económicos; en cuanto a lo social, se dio sin mayor dificultad una especie de absorción y reacomodo a las exigencias estructurales y funcionales en la vida colectiva, familiar e individual. Entre las debilidades estructurales se encontró la crónica dependencia de las transferencias gubernamentales, para lograr una mayor capitalización y autonomía financiera, no solo para ampliar la base de capital físico, sino sus capacidades instaladas.

En resumen, en la zona de estudio se registra una mejora continua en la interlocución con diversos actores locales y foráneos respecto al uso y conservación del centro turístico y los recursos naturales. Esto posibilita mayores alcances de autonomía en la toma de decisiones sobre sus recursos y la transferencia de recursos económicos para favorecer la conservación de su patrimonio natural. Pero esto es parte de un proceso de autogestión, gestión y reapropiación social con todas las fortalezas y debilidades que pueda tener, sin embargo, esto es el reflejo de diez años de paciencia y ardua labor organizativa; habrá que ver su desenvolvimiento en años futuros, cuando la demanda del centro sea mayor. 


\section{Fuentes consultadas}

Allier, Joan y Jordi Roca (2009). Economía ecológica y política ambiental. México: Fondo de Cultura Económica.

Boo, Elizabeth (1991). "Making Ecotourism Sustainable: Recommendations for Planning Development and Management”, en Tensie Whelan (ed.). Nature Tourism, Managing for the environment. Washington: Island Press. Bringas, Nora y Lina Ojeda (2000). "El ecoturismo: ¿una nueva modalidad del turismo de masas?”. Economía, Sociedad y Territorio, II (7), 373-403.

Escobar, Arturo (1999). El final del salvaje. Naturaleza, cultura y política en la antropología contemporánea. Bogotá: Cerec/Instituto Colombiano de Antropología.

García, Juan Carlos (2005). "Manejo terapéutico de enfermos oculares: el tracoma en una localidad tseltal del Oxchuc, Chiapas”. Tesis de maestría. San Cristóbal de Las Casas: Centro de Investigaciones y Estudios Superiores en Antropología Social-Sureste.

Harman, Robert (1990). Cambios médicos y sociales de una comunidad maya-tzeltal. México: Instituto Nacional Indigenista/Consejo Nacional para la Cultura y las Artes.

Hernández, Rosa (2002). "Adaptaciones sociales en torno al ecoturismo en una comunidad indígena en la Selva Lacandona, México”. Tesis de maestría en Ciencias en Recursos Naturales y Desarrollo Rural. San Cristóbal de Las Casas: El Colegio de la Frontera Sur.

Kutay, Karl (1992). "Ecotourism Marketing: Capturing the Demand for Special Interest Nature and Cultural Tourism to Support Conservation and Sustainable Development”. Ponencia presentada en el Tercer Congreso Interamericano de Turismo, Cancún.

Leff, Enrique (2002). Racionalidad ambiental, la reapropiación social de la naturaleza. México: Siglo xxi Editores.

(2007). Racionalidad ambiental. La reapropiación social de la naturaleza.

2a. ed. México: Siglo xxi Editores.

(2009). Ecología y capital; racionalidad ambiental, democracia participativa y desarrollo sustentable. México: Siglo xxi Editores/Universidad Nacional Autónoma de México.

Maldonado, María Isabel (2008). “Concepciones del turismo y territorio entre 
los chuj de Tziscao, Chiapas”. Tesis de maestría en Ciencias en Recursos Naturales y Desarrollo Rural. San Cristóbal de Las Casas: El Colegio de la Frontera Sur.

March, Ignacio (1997). Turismo alternativo en Chiapas: Una alternativa adicional para apoyar el desarrollo social y la conservación de los recursos naturales [en línea]. Encuentro de Organizaciones Indígenas con Proyectos Ecoturísticos, Instituto Nacional Indigenista. Disponible en: www.planeta.com/planeta/98/0298chiapas.html [2005, 4 de julio].

Montoya, Guillermo, José Hernández y Uriel García (2010). Evaluación del programa de conservación y restauración de ecosistemas forestales (PROCOREF-2007). Chiapas: Gobierno del Estado de Chiapas.

Ortiz, Alfonso (1998). Entrevistas semiestructuradas una aplicación en educación primaria. Pamplona: Segundo Simposio Nacional de la Sociedad Española de Investigación en Educación Matemática.

Pardo, Gustavo y Bertha Palomino (2008). "Políticas públicas y ecoturismo en comunidades indígenas de México”. Teoría y Praxis, 5, 33-50.

Ramos, Pedro (2009). "Sistemas de producción agrícolas y medios de vida en el municipio de Oxchuc, Chiapas". Tesis de maestría en Ciencias en Recursos Naturales y Desarrollo Rural. San Cristóbal de Las Casas: El Colegio de la Frontera Sur.

Reygadas, Luis et al. (2006). "Estilos de manejo y gestión de proyectos ecoturísticos en la selva lacandona de Chiapas”, en Rosana Guevara Ramos (coord.). Estudios Multidisciplinarios de Turismo. México: Secretaría de Turismo/Centro de Estudios Superiores en Turismo/Red de Investigadores y Centros de Investigación en Turismo, 71-102.

Sedesol (2001). Microrregiones del municipio de Oxchuc [en línea]. Secretaría de Desarrollo Social. Disponible en: www.sedesol2001.sedesol.gob. $\mathrm{mx} / . . . / 2$ do_trimestre_2001_completo.pdf [23 de agosto, septiembre].

Senkowski, Reinhard (2006). "Concepto de metabolismo cultural para evitar la monocultura en el tren del monoglobalismo”. Cuicuilco, 13 (38), septiembre-diciembre, 23-52. 
- Autogestión y participación local en el centro ecoturístico "Cascadas El Corralito", 0xchuc, Chiapas

Toledo, Víctor (2008). “Metabolismos rurales: hacia una teoría económicoecológica de la apropiación de la naturaleza”. Revista Iberoamericana de Economía Ecológica, 7, 1-26.

Toledo, Víctor, Pablo Alarcón y Lourdes Barón (2002). "Revisualizar lo rural: un enfoque socioecológico”. Gaceta Ecológica, 62, 98-109. 